\title{
Fourier Transform Spectroscopy of Cotton and Cotton Trash
}

\author{
Chanel Fortier \\ United States Department of Agriculture, Agricultural Research Service, \\ Southern Regional Research Center, New Orleans, LA,
}

USA

\section{Introduction}

The application of Fourier Transform (FT) spectroscopy instruments has broadened the knowledge and capabilities of textile researchers to study a host of projects including surface modifications of cotton fibers to impart flame retardant capabilities, monitoring aging effects on ancient cellulosic artifacts (Kavkler et al., 2011; Lojewski et al., 2010), determining the amount of dye fixation to fabrics (Choi, H-M, et al., 1994), and characterization of cotton byproducts during the processing of cotton (Cheng and Biswas, 2011), to name a few. As can be observed from the above examples, the power and versatility of analyzing textiles with FT spectroscopy is proven.

In the textile community, it is very important to characterize cotton quality parameters since this directly affects its potential profitability. Specifically, cotton strength, length, micronaire, fineness, color, and trash amount are conventionally monitored using an Uster ${ }^{\circledR}$ High Volume Instrument (HVI). In regards to the characterization of trash comingled with the cotton fiber, the identity of trash components evaluated with the current HVI system is not possible.

Recently, FT spectroscopy has been instrumental in identifying cotton trash components and foreign matter that are present with cotton fiber (Fortier et al., 2010). The ability to classify, quantify, and ultimately remove cotton trash and foreign matter present with cotton lint has the potential to increase the market value and durability of cotton from its conversion of fiber to yarn. When compared to dispersive instruments, some advantages of FT spectroscopy are higher signal-to-noise capabilities, higher throughput, negligible stray light, continuous spectra, and higher resolution. In addition, FT spectroscopy affords for frequencies in spectra to be measured all at once with more precise wavelength calibrations. FT spectroscopy clearly enhances the data garnered from near-infrared (NIR) and midinfrared (MIR) spectroscopy studies of cotton fiber and cotton trash components. Since Fourier Transform spectroscopy is a broad topic, a brief introduction of its application to mid-infrared and near infrared spectroscopy will be included.

\section{Theory of FT-MIR}

FT-MIR spectroscopy, commonly known as Fourier Transform infrared (FT-IR) spectroscopy, is a branch of vibrational spectroscopy and is a primary method that yields structural 
information about the chemical makeup of a sample. Group absorption frequencies defined by wavelength regions over the range of $400-4000 \mathrm{~cm}^{-1}(25000-2500 \mathrm{~nm})$ can be used to get qualitative information about the functional groups in a sample. Typically, organic functional groups are further defined by molecular vibrations, such as symmetric or antisymmetric stretching, which refer to an oscillation in bond length, or deformation, and bending, which describes an oscillation in bond angle (Pelletier et al., 2010).

The atoms in molecules display three types of energy: translational, rotational, and vibrational. In terms of FT-IR spectroscopy, the degrees of freedom for linear and non-linear molecules are defined by $3 n-5$ and $3 n-6$, respectively. The $3 n$ term is defined by the three dimensions of the Cartesian coordinates for both types of molecules. However, the linear molecule has 2 degrees associated with rotational energy and 3 degrees are associated with translational energy. For the non-linear molecules, 3 of the degrees are rotational and 3 are translational while the remaining corresponds to fundamental vibrations. Therefore, the net degrees of freedom for non-linear molecules are $3 n-6$, and for linear molecules it is $3 n-5$ (Jiskoot, \& Crommelin, 2005). Recently, an attenuated total reflection FT-IR accessory has been widely used. The ATR accessory greatly simplifies or removes sample preparation compared to traditional FT-IR samples employing KBr pellets. Briefly, the ATR accessory operates on the principle that a highly reflective crystal such as diamond or germanium is used as the internal reflective element (IRE). This IRE has a higher index of refraction compared to the sample. The sample and IRE must be in close contact, usually accomplished with a high pressure clamp, to achieve best data acquisition results. This accessory also yields the advantage of the ability to study both solids and liquids (Mirabella, Jr., 1993).

\section{Instrumentation for FT-IR}

Since a detailed description of an FT-IR instrument is beyond the focus of this chapter, the reader is referred to reference (Griffiths \& de Haseth, 2007). Briefly, the FT-IR is based on the Michelson interferometer furnished with a stationary and moving mirror and beamsplitter angled by bisecting the planes of these two mirrors. There is also a source, sensitive detector, and computer (Colthup et al, 1975). The moving mirror is controlled by a transducer. In FTIR spectroscopy, the interferogram in the time domain is converted to the frequency domain through a Fourier transformation, from which the IR spectrum is derived (Perkampus, 1995).

\section{Theory of FT-NIR}

The NIR spectral region encompasses $700-2500 \mathrm{~nm}\left(4000-12000 \mathrm{~cm}^{-1}\right)$ where the regions are defined as first, second, and third overtones or combination bands. In terms of the electromagnetic spectrum, it is situated between the visible and mid-infrared spectral regions. The primary absorbencies observed in the NIR spectral region are for the chemical species $\mathrm{CH}_{\mathrm{i}}, \mathrm{NH}_{\mathrm{i}}$, and $\mathrm{OH}$. However, absorbencies for the carbonyl, sulfydryl, and amide groups can also be detected. In addition, the first, second, and third overtones in the NIR region can be related to fundamental frequencies in the FT-MIR region (Perkampus, 1995).

The wide and overlapping combination and overtone spectral bands typically found using FT-NIR, can complicate the interpretation of its data. In addition, the non-fundamental spectra of FT-NIR, compared to FT-IR, require that calibrations are made using chemometric 
software preferably over a wide range of samples. Chemometrics involves the application of statistics and mathematics to define chemical processes (Moros et al., 2010). With the evolution of chemometrics and high performance computing over the last 40 years, the popularity and use of FT-NIR spectroscopy has increased. Moros and co-workers defined three of the most traditional types of chemometric approaches to vibrational spectroscopy: Pre-processing techniques, classification methods, and regression methods. Pre-processing techniques encompasses pre-processing of the spectral data including derivative math, normalization, and baseline correction. Classification methods involve the application of pattern recognition, be it supervised or unsupervised. Multivariate regression methods include applications of principal component analysis (PCA) and partial least squares (PLS).

\section{Instrumentation of FT-NIR}

A detailed description of a FT-NIR system has been previously reported (Griffiths \& Haseth, 2007; Bell, 1972). Briefly, a typical FT-NIR spectrometer is composed of a source, interferometer, beamsplitter, laser, detector, and optical components. A halogen source is conventionally used. The interferometer includes a moving and stationary mirror perpendicular to each other which modulates the NIR source. A beamsplitter, made up of quartz, calcium fluoride or potassium bromide, splits the NIR signal between the moving and stationary mirror, then recombines the signal and directs it to the detector. The laser, commonly made of helium and neon, controls the moving mirror and aligns the interferometer. NIR spectrometers can be selected based on their response, speed, and detection capabilities. Other optical components, such as mirrors or lenses, can focus or collimate the NIR signal (McCarthy \& Kemeny, 2008).

\section{Comparison of the FT-IR and FT-NIR}

FT-IR affords the use of fundamental frequencies to identify molecular functional groups in both solid and liquid media. Also, when used in conjunction with the ATR accessory, little or no sample preparation is required. However, FT-NIR spectroscopy offers distinct advantages, such as flexibility of multiple sampling systems (e.g. fiber optic probe, rotating sphere) and the option of analyzing powder-size, pepper-size, raw samples (e.g. "sticks"), and large cotton trash samples, which is particularly useful for analyzing a heterogeneous sample such as cotton. Like the ATR/FT-IR sampling system, the FT-NIR sampling system is also non-destructive, easy to use, and has a short analysis time. In addition, FT-NIR instruments are capable of carrying out measurements on samples with longer path lengths than that of FT-IR spectrometers (Perkampus, 1995). These advantages make the study of textiles using FT-NIR, specifically for cotton, very attractive (Rodgers, 2002; Thomasson and Shearer, 1995; Camjani and Muller, 1996; Thibodeaux, 1992; Rodgers and Beck, 2005; Rodgers and Beck, 2009; Rodgers and Ghosh, 2008; Montalvo, et al., 1991).

\section{Cotton fibers}

Cotton fiber is composed mostly of cellulose with a small percentage being made up of waxes, proteins, pectic substances, organic acids, ash, and sugars (Lewin, 1998). The percentage of each non-cellulosic content can vary based on the maturity, cotton variety, and environmental conditions. This desirable chemical makeup along with its physical 
properties makes cotton a very important agricultural crop in both domestic and international markets. The popularity of this natural fiber for many years stems in part from its versatility (used in apparel, bedding, home furnishings, and industrial products), appearance, and performance (Wakelyn et al., 2007).

\section{Cotton trash}

\subsection{Impact of cotton trash on the industry}

Cotton trash present with cotton fiber affects the quality, appearance, price paid by textile mills to producers, yarn and fabric properties, as well as the performance of ginning and spinning equipment (Himmelsbach et al., 2006). In addition, cotton trash identification is important to the textile industry because certain types of trash have different effects on the textile processing of cotton and the marketability of the final fabric. Previous reports have shown the deleterious effects of cotton trash on yarn quality. Yarn breakage during spinning increased nearly $60 \%$ with a $1 \%$ increase in bark content when cotton fiber was processed with standard cleaners and carding equipment (Brashears et al, 1992). Veit and co-workers found a correlation between yarn imperfections and seed coat content present with cotton fiber (Veit et al., 1996). It was also determined that seed coat trash could be implicated in the onset of yarn breaks, deposits in rotor spinning equipment, and nep formation (Frey \& Schneider, 1989). Thus, identifying cotton trash components present with the fiber may lead to more effective instrumental techniques that could be designed to remove the trash content co-mingled with cotton fiber.

\subsection{Cotton trash from field to fabric}

Initially, raw cotton has both fiber and trash material present. In the U.S., cotton is conventionally machine-stripped or machine-picked during harvesting. It is then sent to a gin where the cotton fiber is separated from the cottonseed. The cotton fiber separated from the cottonseed is referred to as the cotton lint. The cotton lint is then cleaned to remove the cotton trash. During the ginning and lint cleaning methods, cotton trash present with the lint tends to become smaller and smaller in size. Next, the cotton lint is classified by the Agricultural Marketing Service (AMS), and sold to textile mills where the yarn and fabric is developed.

It is necessary to clean the raw cotton because the value of cotton lint is strongly influenced by the amount of cotton trash present. Samples from each bale of American cotton are visually examined. Human "classers" give each bale a leaf grade and extraneous matter description. The leaf grade goes from 1-8 with leaf grade 1 having the least amount of trash and leaf grade 8 having the most amount of trash. Obviously, this method's accuracy and precision along with being time-consuming and labor intensive is limited by the subjective evaluation of a human "classer". Thus, instrumental techniques which can reproducibly classify cotton and the trash found with it are desired.

An instrumental method employing the Uster ${ }^{\circledR}$ High Volume Instrument (HVI) yields information on key quality parameters such as length, strength, color, micronaire, length uniformity, as well as trash content. The Shirley Analyzer is another conventional method to analyze cotton trash through and aero-mechanical technique which separate cotton trash from lint. However, these methods do not yield individual trash component identification 
present with the cotton lint. Thus, being able to accurately identify individual cotton trash components would lead to more efficient trash removal and favorable yarn and fabric production.

\section{Non-fourier transform techniques to analyze cotton trash}

\subsection{Geometric/imaging approaches}

Cotton trash has been previously analyzed by a variety of methods. A clustering analysis method was used to identify cotton trash components using sum of squares, fuzzy and neural networks (Xu et.al, 1999). The clustering approach was based on color, shape and size attributes. When comparing the different clustering approaches, the color features were more reliable than the shape and size parameters since trash particles can become smaller during the processing of cotton lint. The neural network clustering method yielded an accurate trash type classification greater than $95 \%$ of the time. However, a limitation of this method was the time required for computation.

Siddaiah and co-workers also classified cotton trash components based on geometry. Their approach involved defining simple geometric shapes (disks, points, arcs, and straight lines) to identify bark leaf, and pepper trash. This technique, which incorporated imaging and intelligent pattern recognition, was highly accurate with $98 \%$ correct classification of the trash types (Siddaiah, 1999).

A machine vision system comparing a camera- and scanner-based imaging technique was developed (Siddaiah et.al, 2006). The Cotton Trash Identification System (CTIS) was compared to conventional instrumentation such as the Uster ${ }^{\circledR}$ HVI, Advanced Fiber Information System (AFIS), and the Shirley Analyzer for measuring cotton trash. It was determined that surface based measurements (CTIS, HVI) had a higher correlation compared to volumetric measurement systems (AFIS and Shirley Analyzer). The CTIS system, calibrated using "classer" calls (human visual identification) was later found to accurately identify trash categories (bark/grass, stick, leaf, and pepper) $97 \%$ of the time.

\subsection{UV-Vis spectroscopy}

Fortier and co-workers investigated the capability of identifying botanical cotton trash types using UV-Vis spectroscopy (Fortier et al., 2011a). Figure 1 shows the result of applying first derivative math to classify cotton and some botanical trash types (hull, leaf, seed coat, and stem). The chemometric software package employed in their study did not allow the use of sub-libraries to distinctly identify the highly similar trash spectra. Thus, $67 \%$ of the individual trash samples were correctly identified as shown in Table 1.

\section{Applications of fourier transform spectroscopy to cotton and cotton trash}

\subsection{Trash effect on spinning efficiency}

Cotton trash has been reported to reduce the efficacy of textile processing (Bargeron et al. 1988, Verschraege, 1989). After cotton fiber is separated from the cottonseed, the fiber is dried, cleaned and converted into yarn through different spinning techniques. The three most commonly used spinning methods are ring, open-end rotor, and vortex spinning. Ring spinning is characterized by a twist inserted into a yarn by a circulating traveler with the 


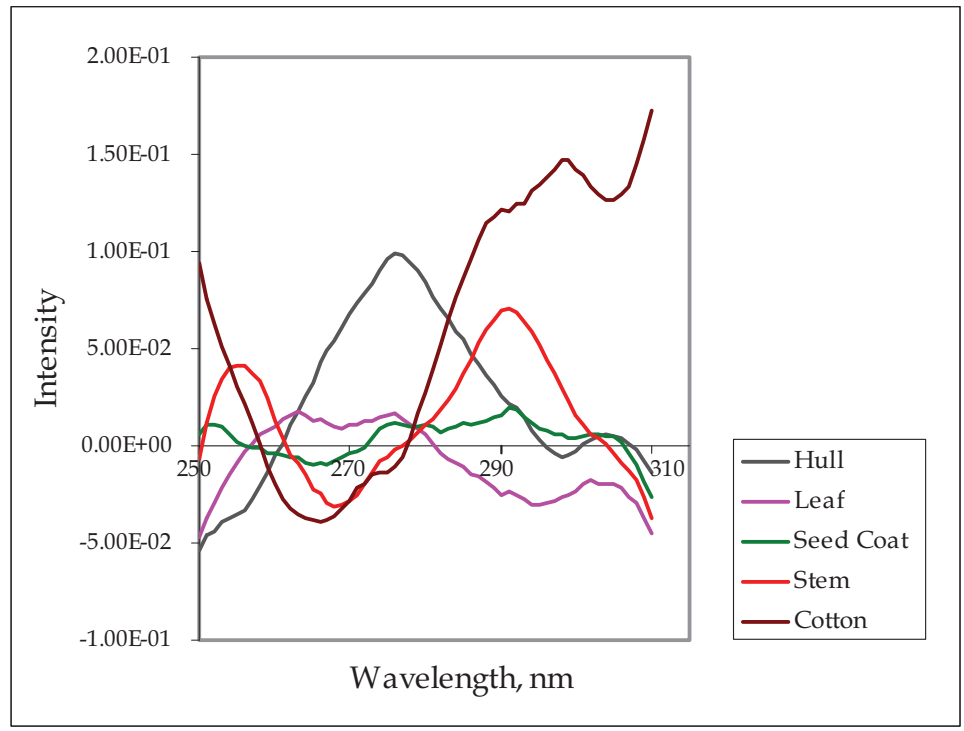

Fig. 1. Average first derivative UV-Vis spectra of cotton, hull, leaf, seed coat and stem botanical trash. Source: Fortier, C., et al., 2011a, Journal of Cotton Science, Vol. 15, pp.174.

\begin{tabular}{|l|c|c|c|}
\hline Trash Type & No. of Samples & No. Correct & \% Correct \\
\hline \hline Hull & 27 & 14 & $52 \%$ \\
\hline Leaf & 30 & 16 & $53 \%$ \\
\hline Seed Coat & 12 & 9 & $75 \%$ \\
\hline Stem & 27 & 25 & $93 \%$ \\
\hline Total & 96 & 64 & $67 \%$ \\
\hline
\end{tabular}

Table 1. UV-Vis identification results of botanical trash types Source: Fortier, C., et al., 2011a, Journal of Cotton Science, Vol. 15, p.173

winding action made possible by a rotating spindle. In open-end rotor spinning, cotton fiber bundles from the sliver (loose piece of cotton fiber) are separated into individual fibers by a roller which opens and an air stream. Vortex spinning has become available commercially in recent years. This spinning type is characterized by cotton fibers being introduced into a spindle orifice by way of air jet technology. One of the three spinning types, open-end rotor spinning efficiency has been found to be greatly influenced by the presence of cotton trash (Baker, et al., 1994).

The presence of cotton contamination in the rotor groove has been associated with the onset of yarn breakage, thick places in the yarn, and yarn entanglement (Thibodeaux \& Baril, 1981; McCreight et al., 1997). Compounding this issue is the tendency for trash types to become smaller and smaller in size making it virtually impossible to visibly identify individual cotton trash components. Foulk and co-workers carried out an FT-IR classification study where cotton trash components (e.g. hull vein, hull outside, hull stem, hull inside, shale vein, shale) were evaluated based on color differences (Foulk et al., 2004). Pima and upland cotton varieties having widely different trash amounts and moisture levels were analyzed 
using a diverse set of ginning methods. The objective of this study was to identify the type of cotton and trash type or types built up in the rotor groove. The rotor dust was collected and analyzed by FT-IR and compared to the spectral database (calibration set). In the spectral database, the top five matches were provided for each sample. Classification results were determined by counting the number spectral matches for a particular type of trash as shown in Figure 2. The trash collected in the rotor grove was determined to be largely composed of shale and hull trash types (Foulk, 2004).

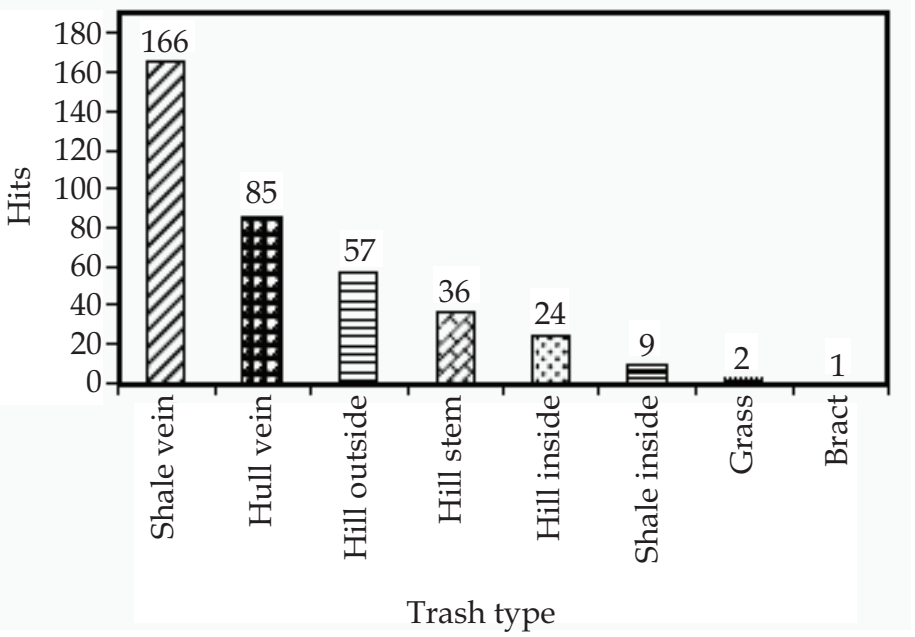

Fig. 2. FT-IR spectra matched hits for open end spinning rotor dust. Source: Foulk, J. et al, 2004, Journal of Cotton Science, Vol. 8, p.249

\subsection{Size effects and heat treatment}

Allen and co-workers conducted an ATR/FT-IR spectroscopy study to analyze botanical cotton trash (leaf, seed coat, stem, and hull) subjected to different temperatures and particle sizes typically observed in a ginning or textile mill environment (Allen et al., 2007). During ginning the cotton fiber temperature is raised to aid in the separation of cotton trash from the lint. Also, raw trash components become smaller and smaller due to mechanical treatment of the cotton fiber. This effect makes it very challenging to determine the origin of the trash particles.

The cotton trash components were evaluated at elevated $\left(149^{\circ} \mathrm{C}\right)$ and standard room temperature conditions $\left(22^{\circ} \mathrm{C}\right)$. The FT-IR spectral data was obtained at $21^{\circ} \mathrm{C}$ using a benchtop FT-IR instrument fitted with an ATR accessory. To determine the effects of the two temperature settings, the ratio of the area under the total spectrum to the area under each of the IR bands of interest were calculated. The assigned ATR/FT-IR bands included in this study were based on the O-H stretch at $3300 \mathrm{~cm}^{-1}$, the C-H asymmetric stretch at $2900 \mathrm{~cm}^{-1}$, the $\mathrm{C}-\mathrm{H}$ symmetric stretch at $2850 \mathrm{~cm}^{-1}$, the $\mathrm{C}=\mathrm{O}$ stretch of a carboxylic acid and ester at $1700 \mathrm{~cm}^{-1}$, and the $\mathrm{C}=\mathrm{O}$ stretch of an acid salt at $1600 \mathrm{~cm}^{-1}$ (Chung et al., 2004; Silverstein and Webster, 1998). All heated samples were allowed to return to room temperature to observe any irreversible changes in the FT-IR spectra. No change in trash color was observed in 
pepper-sized trash $(0.841 \mathrm{~mm}$ standard diameter). However, over the $\mathrm{O}-\mathrm{H}$ and $\mathrm{C}-\mathrm{H}$ stretching frequencies (2900 and $3300 \mathrm{~cm}^{-1}$ ), the stem and hull trash had an appreciable change (Figures 3 and 4) compared to the leaf and seed coat spectra (data not shown). For the IR bands representing the $\mathrm{C}=\mathrm{O}$ stretching frequency $\left(1600\right.$ and $\left.1700 \mathrm{~cm}^{-1}\right)$, the seed coat trash component has the most noticeable spectral difference (Figure 5) compared to the leaf, hull, and stem components. The relevance of this observation is that the seed coat may have volatile aliphatic esters which are generated with heat.

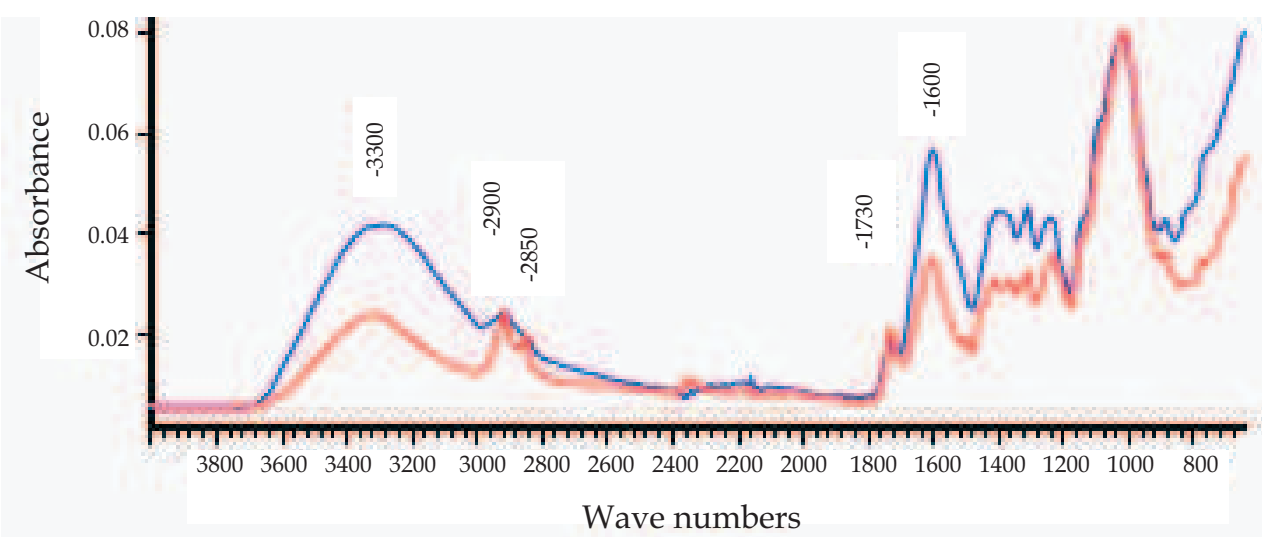

Fig. 3. The effects of heat treatment on the ATR/FT-IR spectra of the pepper-size stem samples. The blue curve represented the spectra at standard conditions and the red curve represebts samples heated to $149^{\circ} \mathrm{C}$ for 20 minutes then allowed to return to standard conditions prior to analyzing. Source: Allen et al., 2007, Journal of Cotton Science, Vol. 11, p.72

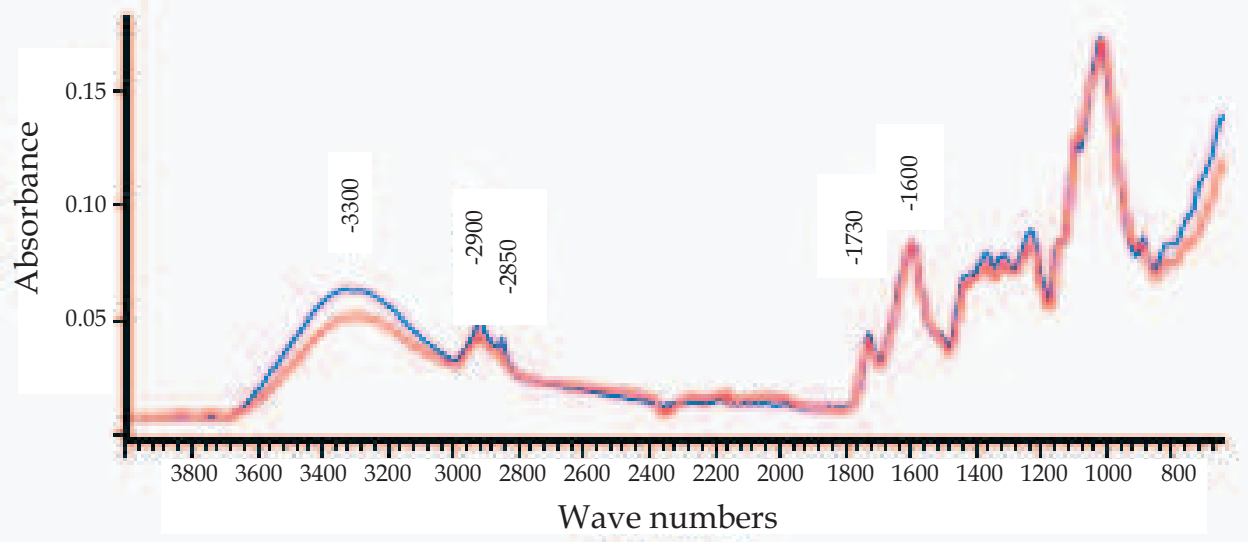

Fig. 4. The effects of heat treatment on the ATR/FT-IR spectra of the pepper-size hull samples. The blue curve represented the spectra at standard conditions and the red curve represents samples heated to $149^{\circ} \mathrm{C}$ for 20 minutes then allowed to return to standard conditions prior to analyzing. Source: Allen et al., 2007, Journal of Cotton Science, Vol. 11, p.72 


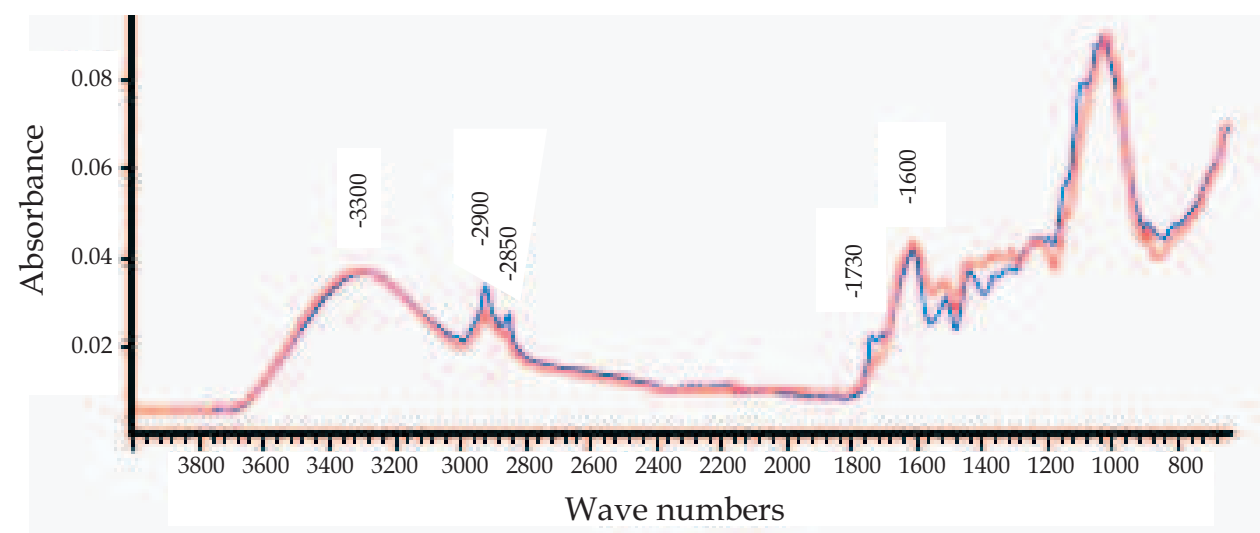

Fig. 5. The effect of heat treatment on the ATR/FT-IR spectra of the pepper-size seed coat samples. The blue curve represented the spectra at standard conditions and the red curve represents samples heated to $149^{\circ} \mathrm{C}$ for 20 minutes then allowed to return to standard conditions prior to analyzing. Source: Allen et al., 2007, Journal of Cotton Science, Vol. 11, p.72

In terms of the effect of particle size (powder, pepper, and raw), distinct spectral FT-IR differences over the spectral range of 3500 to $2800 \mathrm{~cm}^{-1}$ were observed for the stem, (Figure 6) leaf and hull samples (data not shown), but for the seed coat trash type (Figure 7) no observable differences were found. Pepper and powder-sized trash samples were generated using 20 (0.841 $\mathrm{mm}$ std. diameter) and 80 (0.177 $\mathrm{mm}$ std. diameter) meshes, respectively.

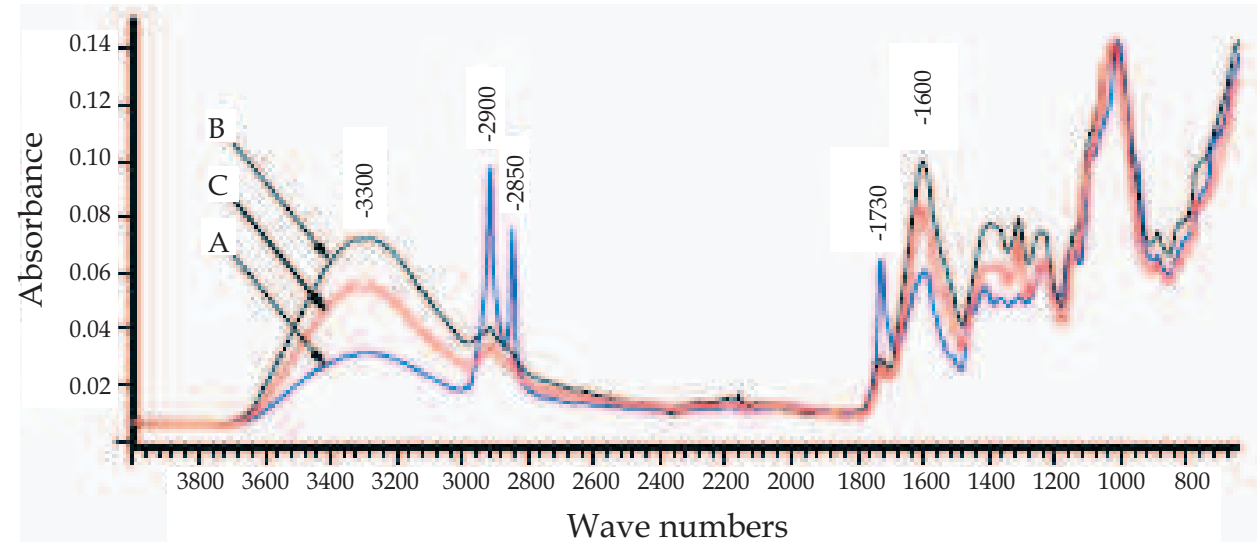

Fig. 6. The effect of size reduction on the ATR/FT-IR spectra of the stem sample, including ground raw size (blue, A), pepper-size (black, B), and powder size (red, C) Source: Allen et al., 2007, Journal of Cotton Science, Vol. 11, p.71

Overall, it was concluded that size and heat treatment can affect the FT-IR spectra of cotton trash types. Thus, spectral databases used for classifying these components should include spectra accounting for these physical applications. 


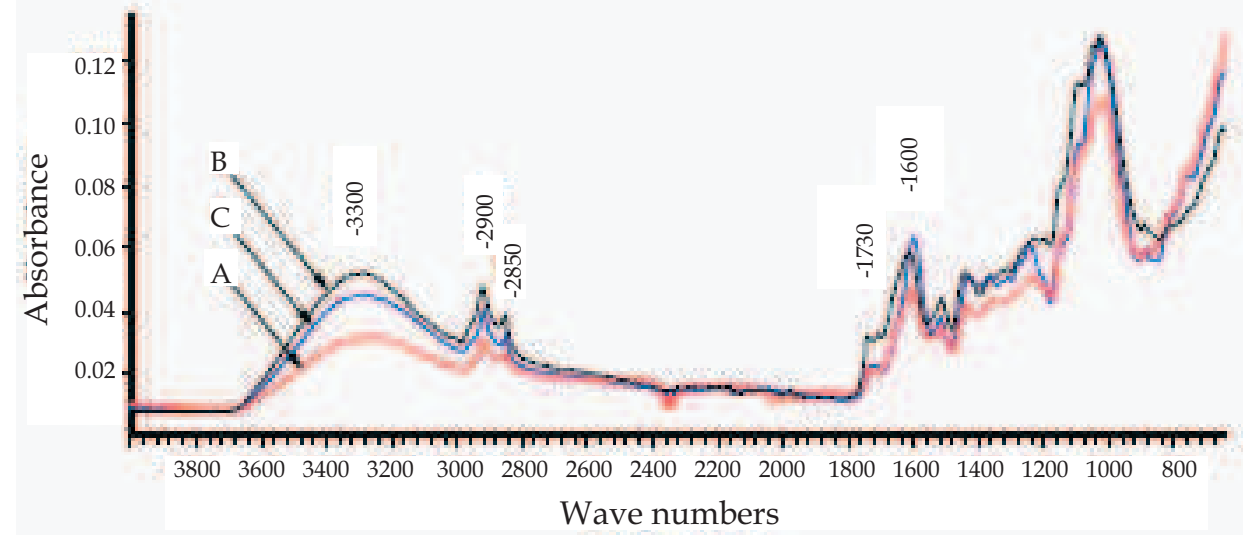

Fig. 7. The effect of size reduction on the ATR/FT-IR spectra of the seed coat sample, including ground raw size (blue, A), pepper-size (black, B), and powder size (red, C) Source: Allen et al., 2007, Journal of Cotton Science, Vol. 11, p.71

\subsection{Botanical and synthetic cotton trash}

To expand on the proven utility of applying ATR/FTIR as a technique to specifically identify cotton trash, Himmelsbach and co-workers did an extensive study on botanical cotton trash and other foreign matter both organic (other fibers, yarns, etc.) and synthetic (plastic bags, film, etc.) that can become co-mingled with cotton lint during its harvesting, ginning, and processing (Himmelsbach et al., 2006). The development of an FT-IR spectral database yielded highly accuracte identification of cotton trash and foreign matter serving as a "proof of concept" of the utility of this instrumental method. Fortier and co-workers later compared their FT-IR results to that of this preliminary FT-IR study by Himmelsbach and co-workers (Fortier et al., 2010). The two studies yielded comparable results. Representative FT-IR absorbance spectra results of cotton, hull, leaf, seed coat, and stem are shown in Figure 8. The spectra are based on three replicates averaged with a resolution of 8 $\mathrm{cm}^{-1}$ and 128 scans.

\subsection{Fourier-transform near-infrared spectroscopy of botanical cotton trash}

More recently, the application of FT-NIR spectroscopy has also been employed to identify individual botanical trash components (hull, leaf, seed coat, and stem) in a spectral library. Pepper-sized and powder-sized pure trash components were included in the calibration set. While pepper-sized, powder-sized and raw samples of different varieties were included in the prediction set. Specifically, the calibration set was different from the prediction set in that the corresponding powder and pepper samples in the calibration set were represented as the opposite powder and pepper samples in the prediction set. There were 9 different varieties of trash samples taken from Mississippi, New Mexico, and South Carolina. The cotton trash varieties are denoted by the first two letters from the state the samples were acquired in and the last letter as the sample variety as shown in Table 2. Sample measurements were taken by directly placing a solid probe in contact with the trash samples. When creating the calibration set (spectral library), multiple wavelength regions 


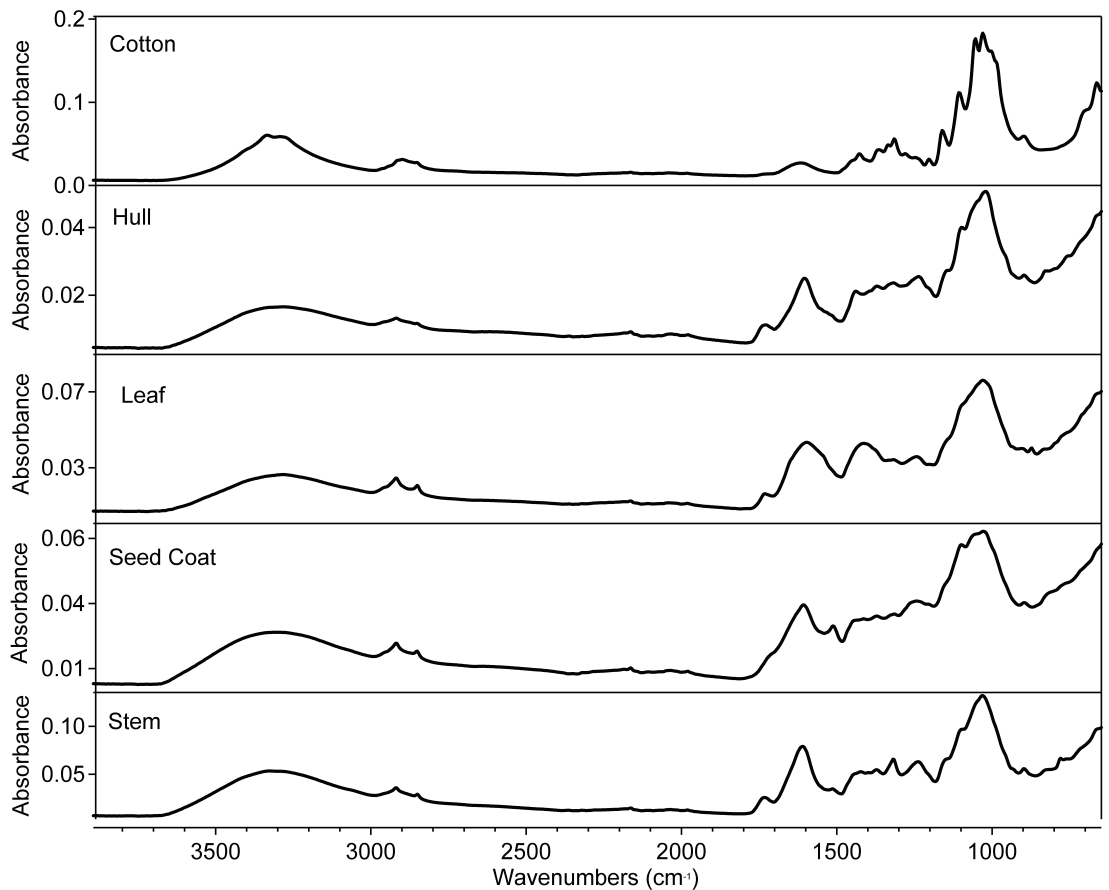

Fig. 8. Average FT-MIR absorbance spectra of cotton and cotton trash components at a resolution of $8 \mathrm{~cm}^{-1}$ with 128 scans Source: Fortier et al., 2010, Textile Research Journal, Vol. 81 , p. 233

(full spectra range, and small spectral ranges) and pre-processing methods (vector normalization and derivative math) were investigated to optimize the correct identification of the pure botanical trash types in the prediction set.

Figure 9 show the results of comparing the average FT-NIR absorbance spectra for a clean cotton reference to pure botanical trash components. The "clean" cotton has specific bands represented at $1490 \mathrm{~nm}, 1930 \mathrm{~nm}$, and $2100 \mathrm{~nm}$. Over the spectral region of $1490 \mathrm{~nm}$ to 1600 $\mathrm{nm}$ which is referred to as the first overtone of the hydroxyl, the cotton band is more uniquely defined compared to the cotton trash. The band at 1450-1490 $\mathrm{nm}$ represents the $\mathrm{OH}$ stretch first overtone due to moisture and indicates the presence of $\mathrm{OH}$ groups in cotton. There was considerable overlap of cotton and cotton trash spectra at the very intense moisture band present at $1930 \mathrm{~nm}$ which is also the $\mathrm{OH}$ bend stretch and water deformation combination band. At $2100 \mathrm{~nm}$, which is the $\mathrm{OH}$ bend/CO stretch combination, the band representing $\mathrm{OH}$ groups present in cotton, and to a lesser extent moisture, had considerable overlap with the cotton trash spectra even though the intensity of the cotton band is more pronounced. In terms of the cotton trash, there was considerable overlap throughout the entire spectral region with a defining peak over the spectral region of $1400 \mathrm{~nm}$ to $1500 \mathrm{~nm}$ which did not include a cotton peak. Even though cotton had distinctive spectral bands, the investigation was continued to gain non-overlapping spectral identity for all the trash components with a validation report showing no confused components (Fortier et al., 2010). 
Thus, the investigation was expanded to include different wavelength ranges and other preprocessing methods. First derivative math was then employed to uniquely identify the botanical trash types, and cotton as shown in Figure 10. This pre-processing was able to distinctly identify cotton, leaf, and stem. However, a sub-library consisting of hull and seed coat was necessary to distinguish these trash types due to their very similar spectra as depicted in Figure 11. Overall, result in Table 3 reveals the trash types were correctly identified $98 \%$ of the time. The 2 misidentifications for the seed coat was a direct effect due to the spectral similarity of the hull and seed coat trash types. Raw samples of each botanical trash type was also investigated to determine the sample-size effect on correct identification of hull, leaf, seed coat, and stem pure trash types. Table 4 reveals the results of this experiment. The result for the raw stem trash misidentifications could be explained by the irregular shape of the stems during sampling with the solid fiber optic probe.

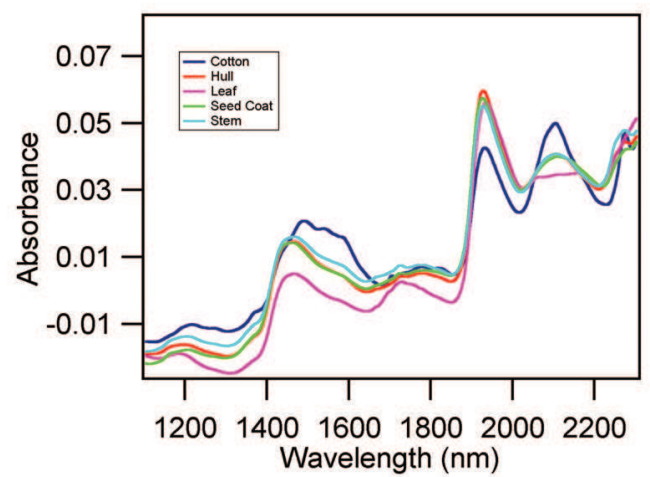

Fig. 9. Average FT-NIR absorbance spectra for "clean" cotton and cotton trash samples over entire spectral range 1100-2400 $\mathrm{nm}$ where cotton can be identified but cotton trash components are overlapping. Vector normalization and standard method pre-processing was applied Source: Fortier et al., 2010, Textile Research Journal, Vol. 81, p. 234

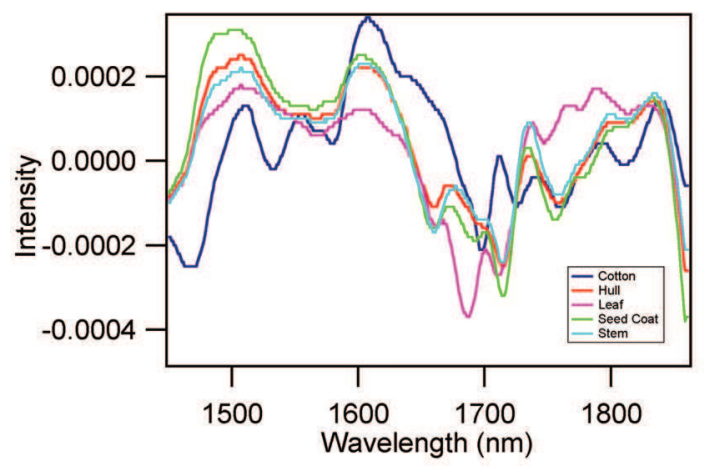

Fig. 10. Average FT-NIR spectra for cotton and cotton trash over the narrow spectral range of (1427-1867 $\mathrm{nm}$ ) where cotton and cotton trash components are uniquely identified except for hull and seed coat. A factorization and first derivative pre-processing method was applied Source: Fortier et al., 2010, Textile Research Journal, Vol. 81, p. 236 


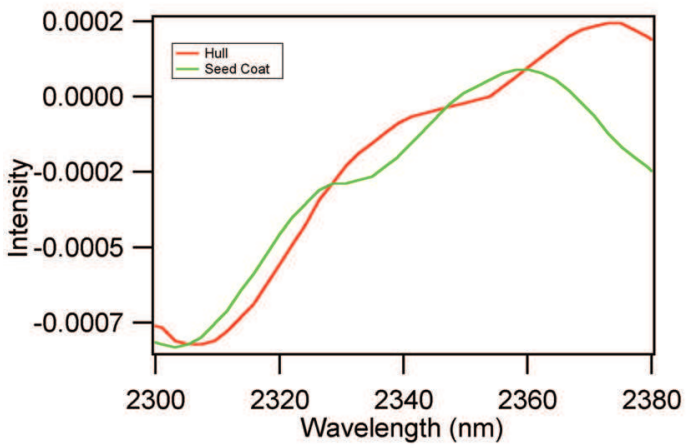

Fig. 11. Average first derivative spectra from sub-library for hull and seed coat. Source: Fortier et al., 2010, Textile Research Journal, Vol. 81, p. 236

\begin{tabular}{|l|c|c|c|c|}
\hline Cotton Trash Variety and Size & \multicolumn{4}{|c|}{ Trash Types } \\
\hline MSA (powder) & Hull & Leaf & Seed Coat & Stem \\
\hline NMA (pepper) & Hull & Leaf & NS & Stem \\
\hline NMB (powder) & Hull & Leaf & Seed Coat & Stem \\
\hline NMC (pepper) & Hull & Leaf & Seed Coat & Stem \\
\hline SCA (pepper) & Hull & Leaf & Seed Coat & Stem \\
\hline SCB (powder) & Hull & Leaf & Seed Coat & Stem \\
\hline SCC (pepper) & Hull & NS & Seed Coat & Stem \\
\hline SCD (pepper) & Hull & Leaf & Seed Coat & Stem \\
\hline SCE (powder) & Hull & Leaf & Seed Coat & Stem \\
\hline MSA, NMB,NMA,NMC,SCA & \multicolumn{4}{|c|}{ Raw seed meat } \\
\hline
\end{tabular}

NS = no sample. (The cotton trash varieties are denoted by the first two letters from the state the samples were acquired in and the last letter as the sample variety (MSA = Mississippi DP555, NMA = New Mexico DP555, NMB = New Mexico AC151799, NMC = New Mexico Unknown, SCA = South Carolina DP458, SCB = South Carolina DP555, SCC $=$ South Carolina DP555a, SCD = South Carolina FM989, SCE = South Carolina PM1218).

Table 2. Calibration set of cotton trash samples. Source: Fortier et al., 2010, Textile Research Journal, Vol. 81, p. 231

\begin{tabular}{|l|c|c|c|}
\hline Prediction Set & \multicolumn{3}{|c|}{ Individual Powder and Pepper Samplesa } \\
\hline & \%Correct & Number of samples & Number Correct $^{\text {Num }}$ \\
\hline Hull & $100 \%$ & 27 & 27 \\
\hline Leaf & $100 \%$ & 27 & 27 \\
\hline Seed Coat & $91.7 \%$ & 24 & 22 \\
\hline Stem & $100 \%$ & 27 & 27 \\
\hline Total & $98.1 \%$ & 105 & 103 \\
\hline
\end{tabular}

Table 3. NIR Identification by Cotton Trash Type for Powder and Pepper samples. Source: Fortier et al., 2010, Textile Research Journal, Vol. 81, p. 236 


\begin{tabular}{|l|c|c|c|}
\hline Prediction Set & \multicolumn{3}{|c|}{ Average Raw Samples $^{\mathbf{a}}$} \\
\hline & \%Correct & Number of samples & Number Correct \\
\hline Hull & $100 \%$ & 9 & 9 \\
\hline Leaf & $100 \%$ & 9 & 9 \\
\hline Seed Coat & $100 \%$ & 8 & 8 \\
\hline Stem & $77.78 \%$ & 9 & 7 \\
\hline Total & $94.3 \%$ & 35 & 33 \\
\hline
\end{tabular}

Table 4. NIR Identification by Cotton Trash Type for Raw samples. Source: Fortier et al., 2010, Textile Research Journal, Vol. 81, p. 236

\subsection{Seed meat addition to botanical trash library}

Fortier and co-workers added seed meat to the FT-NIR spectral library to make it more robust (Fortier et al., 2011b). The seed meat spectra (data not shown) was quite different from the original trash components in the FT-NIR spectral library (hull, leaf, seed coat, and stem) Thus, simply adding the seed meat spectra to the existing library caused some misidentifications by making the other botanical trash components' thresholds overlap. As a result, a different approach was necessary to improve the number of correct identifications in the prediction set. A "top down" approach was employed where the seed meat was isolated first in the library. Next, the cotton and botanical trash types were included in the spectral library, and a second sub-library was made to separate the hull and seed coat, due to their highly similar spectra. The end result was that $100 \%$ of the trash types were identified correctly in the prediction set (data not shown).

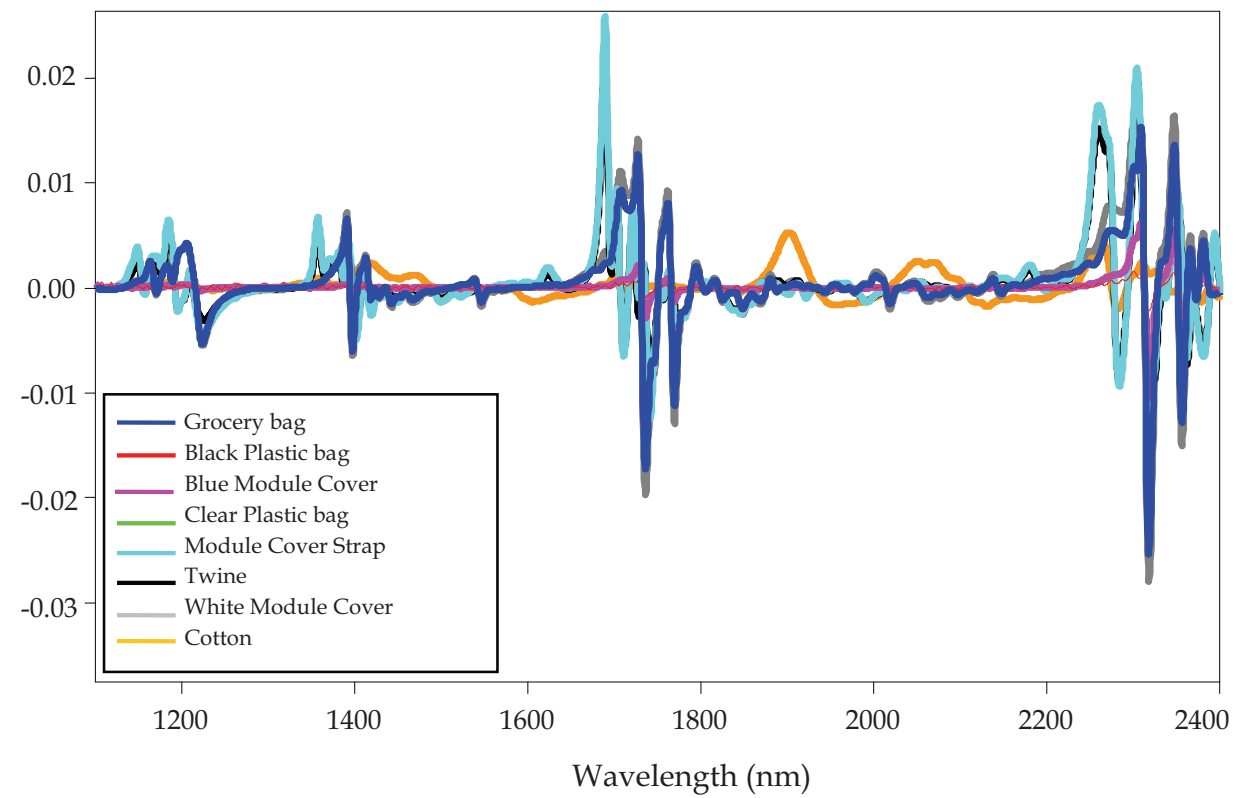

Fig. 12. Average first derivative spectra of field trash and cotton. Source: Fortier et al., 2011b, Journal of Cotton Science, in press 


\subsection{Field trash addition to FT-NIR spectral library}

Field trash refers to any trash found in a cotton field which is not originating from the cotton plant. Recently, FT-NIR spectroscopy was used to identify field trash samples including a grocery bag, black plastic bag, blue module cover, clear plastic bag, module cover strap, twine, and white module cover (Fortier et al., 2011b). Three replicates were acquired for each trash type. Figure 12 shows the average first derivative spectra of cotton and field trash types. Applying a "top down" approach, Fortier and co-workers added field trash samples, to the FT-NIR spectral library (Fortier et al., 2011b). First, the seed meat and field trash were isolated from the rest of the botanical trash library. Next, a sub-library of the cotton and botanical trash types was designed. Finally a second sub-library to separate hull and seed coat was developed. The identification results can be found in Table 5. Overall, greater than 98\% correct identifications were achieved.

\begin{tabular}{|l|c|c|c|}
\hline Prediction Set & \multicolumn{3}{|c|}{ Individual Powder, Pepper, and Field Trash Samples } \\
\hline Trash Type & $\%$ Correct & Number of Samples & Number Correct \\
\hline Hull & $100 \%$ & 27 & 27 \\
\hline Leaf & $100 \%$ & 27 & 27 \\
\hline Seed Coat & $95.24 \%$ & 21 & 20 \\
\hline Seed Meat & $91.67 \%$ & 12 & 11 \\
\hline Stem & $100 \%$ & 27 & 27 \\
\hline Total Botanical Trash & $98.25 \%$ & 114 & 112 \\
\hline Grocery Bag & $100 \%$ & 2 & 2 \\
\hline Black Plastic Bag & $100 \%$ & 2 & 2 \\
\hline Blue Module Cover & $100 \%$ & 2 & 2 \\
\hline Clear Plastic Bag & $100 \%$ & 2 & 2 \\
\hline Module Cover Strap & $100 \%$ & 2 & 2 \\
\hline Twine & $100 \%$ & 2 & 2 \\
\hline White Module Cover & $100 \%$ & 2 & 14 \\
\hline Total Field Trash & $100 \%$ & 14 & 126 \\
\hline Overall Total Trash & $98.44 \%$ & 128 & 2 \\
\hline
\end{tabular}

Table 5. NIR Identification by Cotton Trash Type for Individual Powder and Pepper samples adding seed meat and field trash. Source: Fortier et al., 2011b, Journal of Cotton Science, in press

\section{Summary}

This chapter has summarized the application of FT spectroscopy towards the identification and classification of cotton trash components which are found present with cotton lint. The successes reported herein were not possible with conventional techniques such as using the HVI and Shirley Analyzer. In the future, the feasibility of using FT techniques can benefit those in the textile industry such as farmers, ginners, spinners and merchants by providing a well-defined cotton product which has a minimal amount of trash and a high market value. 


\section{References}

Allen, A., Foulk, J. \& Gamble, G. 2007. Preliminary Fourier-Transform Infrared Spectroscopy Analysis of Cotton Trash, Journal of Cotton Science, Vol.11, pp.68-74, ISSN 15236919.

Baker, R., Price, J., \& Robert, K. 1994, Gin and mill cleaning for rotor spinning, Transactions of the American Society of Agricultural Engineers, Vol. 37, No.4, pp. 1077-1082, ISSN 0001-2351.

Bargeron, J., Rayburn, \& S. Griffith, S. 1988. Effects of grass contaminated with cotton on yarn manufacturing, Transactions of the American Society of Agricultural Engineers, Vol.31, No.1, pp.2-4, ISSN 0001-2351.

Bell, R.J. 1972. Introductory Fourier Transform Spectroscopy, Academic, ISBN 0120851504, New York, New York.

Brashears, A., Baker, R., Bragg, C., \& Simpson, C., 1992. Effect of bark on spinning efficiency of cotton, Proceedings of Beltwide Cotton Conference, ISSN 10592644, Nashville, TN, January 1992, pp.1218-1219.

Camajani, N., \& Muller, D., 1996. Textile Analysis by FT-NIR: Fourier Transform Near Infrared Spectroscopy, In: Textile Applications of Near Infrared Technology: American Association of Textile Chemists and Colorists Symposium, Rodgers, J., Beck, K., Howell, H., \& Hunter, W., pp. 1-12, Asheville, North Carolina.

Cheng, H. \& Biswas, A. 2011. Chemical modification of Cotton-Based Natural Materials: Products from Carboxymethylation. Carbohydrate Polymers, Vol 84, No. 3, pp.10041010, ISSN 01448617.

Choi, H-M., Srinivasan, M., \& Morris, N. 1994. Single-Step Dyeing and Finishing Treatment of Cotton with 1,2,3,4-Butanetetracarboxylic acid. Journal of Applied Polymer Science, Vol. 54, pp.2107-2118, ISSN 00218995.

Chung, C., Myunghee, L. \& Choe, E. 2004. Characterization of cotton fabrics scouring by FT-IR ATR spectroscopy. Carbohydrate Polymers, Vol. 58, No.4, pp.417-420, ISSN 0144-8617.

Colthup, N., Daly, L., \& Wiberley, S. 1975. Introduction to Infrared and Raman spectroscopy, Academic Press, ISBN 0-12-182552-3, New York, New York.

Fortier, C., Rodgers, J., Cintron, M. S., Cui, X. \& Foulk, J. 2010. Identification of Cotton and Cotton Trash Components by Fourier Transform Near-Infrared Spectroscopy. Textile Research Journal, Vol.81, pp. 230-238, ISSN 0040-5175.

Fortier, C., Rodgers, J., \& Foulk, J. 2011a. Investigation of the Impact of Instrumental and Software Applications on Cotton and Botanical Trash Identification by UltravioletVisible and Near-Infrared Spectroscopy, Journal of Cotton Science, Vol. 15, pp.170178, ISSN 15236919.

Fortier, C., Rodgers, J., Foulk, J., \& Whitelock, D. 2011b. Near-Infrared classification of cotton lint, botanical and field, Journal of Cotton Science, in press, ISSN 15236919.

Foulk, J., McAlister, D., Himmelsbach, D. \& Hughs, E. 2004. Mid-Infrared Spectroscopy of Trash in Cotton Rotor Dust. Journal of Cotton Science, Vol.8, pp.243-253, ISSN 15236919.

Frey, M., \& Schneider, U. 1989. Possibilities of Removing Seed Coat Fragments and Attached Fibers in the Spinning Process, Melliand Textilberichte International Textile Reports, Vol. 70, No. 5, pp. 315-317, ISSN 0341-0781.

Griffiths, P., De Haseth, J. 2007. Fourier Transform Spectrometry, 2nd edition, John Wiley and Sons, ISBN 978-0-471-19404-0, Hoboken, New Jersey. 
Himmelsbach, D., J. Hellgeth, D. McAlister. 2006. Development and Use of an Attenuated Total Reflectance/Fourier Infrared (ATR/FT-IR) Spectral Database to Identify Foreign Matter in Cotton. Journal of Agricultural and Food Chemistry, Vol.54, pp.74057412, ISSN 0021-8561.

Jiskoot, W., Daan, J., \& Crommelin, A. 2005. Methods for structural analysis of protein pharmaceuticals, Library of Congress, ISBN 0-9711767-2-8, Arlington, VA.

Kavkler, K., Smit, Z., Jezersek, D., Eichert, D., \& Demsar, A. 2011. Investigation of Biodeteriorated Historical Textiles by Conventional and Synchrotron Radiation FTIR spectroscopy. Polymer Degradation \& Stability, Vol. 96, pp.1081-1086, ISSN 0141-3910.

Lewin, M. \& Pearce, E. 1998. Handbook of Fiber Chemistry, 2nd edition, Marcel Dekker, Inc., ISBN 0-8247-9471-0, New York, New York.

Lojewski, T., Miskowiec, P., Missori, M., Lubanska, A., Proniewicz, L., \& Lojewska, J. 2010. FTIR and UV/Vis as Methods for Evaluation of Oxidative Degradation of Model Paper: DFT Approach for Carbonyl Vibrations. Carbohydrate Polymers, Vol. 82, pp.370-375, ISSN 0144-8617.

McCarthy, W. \& Kemeny, G. 2008. Fourier Transform Spectrophotometers in the NearInfrared, In: Handbook of Near-Infrared Analysis, 3rd Edition, Burns, D., Ciurczak, E., pp. 79-91CRC Press, ISBN 978-0-8493-7393-0, Boca Raton, Florida.

McCreight, D., Feil, R., Booterbaugh, J., \& Backe, E. 1997, Short Staple Yarn Manufacturing, Carolina Academic Press, ISBN 9780890898536, Durham, NC.

Mirabella, Jr., F. M. 1993. Internal Reflection Spectroscopy, Marcel Dekker, ISBN 0-8247-8730-7, New York, New York.

Montalvo, J., Faught, S., \& Buco, S. A 1991. Comparative Study of NIR Diffuse Reflectance of Cottons Grouped According to Fiber Cross-Sectional Dimensions, Part III. Experimental. Applied Spectroscopy, Vol. 45, No.5, pp.795-807, ISSN 0570-4928.

Moros, J., Garrigues, S. \& de la Guardia, M. 2010. Trends in Analytical Chemistry, Vol.29, No.7, pp. 578-591, ISSN 0165-9936.

Pelletier, M., \& Pelletier, C.C. 2010. Spectroscopic Theory for Chemical Imaging, In "Raman, Infrared, and Near-Infrared Chemical Imaging", Šašić, S., \& Ozaki, Y., pp.1-20, John Wiley and Sons, ISBN 978-0-470-38204-2, Hoboken, New Jersey.

Perkampus, H.-H. 1995. Encyclopedia of Spectroscopy, VCH Verlagsgesellschaft mbH, ISBN 3527-29281-0, Weinheim, Germany.

Rodgers, J. 2002. Influences of Carpet and Instrumental Parameters on the Identification of Carpet Face Fiber by NIR. American Association of Textile Chemists and Colorists Review, pp. 27-32, ISSN 1532-8813.

Rodgers, J. E. \& Beck, K. 2005. Rapid Determination by NIR of the Cotton Content of Blend Fabrics after Dyeing, Proceedings of the Beltwide Cotton Conference, ISSN 10592644, New Orleans, LA,January 2005, pp. 2731-2736.

Rodgers, J. \& Beck, K., NIR 2009. Characterization and Measurement of the Cotton Content of Dyed Blend Fabrics. Textile. Research Journal, Vol. 79, No.8, pp.675-686, ISSN 0040-5175.

Rodgers, J. \& Ghosh, S., 2008. NIR Analysis of Textiles, In: Handbook of Near-Infrared Analysis, 3rd edition, Burns, D. \& Ciurczak, E. pp 485-520; CRC Press, ISBN 978-0-8493-73930 , Boca Raton, Florida. 
Siddaiah, M., Lieberman, M., Prasad, N., \& Kreinovich, V. 1999. A Geometric Approach to Classification of Trash in Ginned Cotton. Departmental Technical Reports, Paper 581, pp. 77-82.

Siddaiah, M., Hughs, E., Lieberman, M., \& Foulk, J. 2006. Proceedings of the Beltwide Cotton Conference, ISSN 10592644, San Antonio, TX, January 2006, pp.1926-1937.

Silverstein, R. \& Webster, F. 1998. Spectrometric identification of organic compounds, John Wiley \& Sons Ltd., ISBN 0-471-39362-2, Toronto, Canada.

Thibideaux, D., \& Baril, A. 1981. Laboratory techniques for predicting cotton dust residues in open-end spinning. Textile Research Journal, Vol.51, No.11, pp.688-695, ISSN 00405175 .

Thibodeaux, D. 1992. NIR as a Tool for Measuring Cotton Quality., International Cotton Conference, Bremen, Germany, March 1992, pp. 27-38.

Thomasson, J. \& Shearer, S. 1995. Correlation of NIR Data with Cotton Quality Characteristics. Transactions of the American Society of Agricultural Engineers, Vol. 38, No. 4, pp. 1005-1010 ISSN 0001-2351.

Veit, D., Hormes, I., Bergmann, J., \& Wulfhorst, B., 1996. Image Processing as a Tool to Improve Machine Performance and Process Control, International Journal of Clothing Science and Technology, Vol. 8, No. 1-2, pp. 66-72, ISSN 0955-6222.

Verschaege, L. 1989. Cotton Fibre Impurities: Neps, Motes, and Seed Coat Fragments, Centre for Agricultural Bioscience International: International Conference on Analytical Chemistry: Review Articles on Cotton Production Research No. 1. ISBN 08-5198 633-1, Wallingford, UK.

Wakelyn, P., Bertoniere, N., French, A., Thibodeaux, D., Triplett, B., Rousselle, M-A., Goynes, Jr., W., Edwards, J., Hunter, L., McAlister, D., \& Gamble, G. 2007. Cotton Fiber Chemistry and Technology, CRC Press, ISBN -10: 1-4200-4587-3, Boca Raton, FL.

Jiskoot, W., Daan, J., \& Crommelin, A. 2005. Methods for structural analysis of protein pharmaceuticals, Library of Congress, ISBN 0-9711767-2-8, Arlington, VA.

Xu, B., Fang, C. \& Watson, M. 1999. Clustering Analysis for Cotton Trash Classification, Textile Research Journal, Vol.69, No.9, pp.656-662, ISSN 0040-5175. 


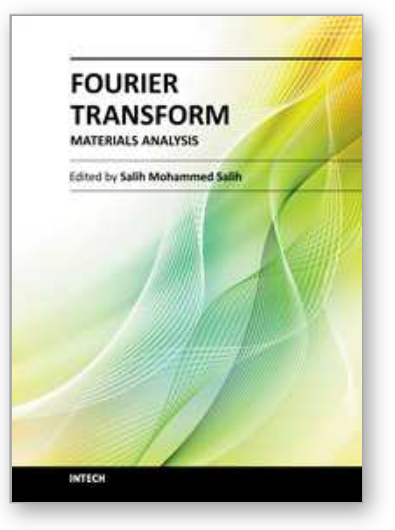

\author{
Fourier Transform - Materials Analysis \\ Edited by Dr Salih Salih
}

ISBN 978-953-51-0594-7

Hard cover, 260 pages

Publisher InTech

Published online 23, May, 2012

Published in print edition May, 2012

The field of material analysis has seen explosive growth during the past decades. Almost all the textbooks on materials analysis have a section devoted to the Fourier transform theory. For this reason, the book focuses on the material analysis based on Fourier transform theory. The book chapters are related to FTIR and the other methods used for analyzing different types of materials. It is hoped that this book will provide the background, reference and incentive to encourage further research and results in this area as well as provide tools for practical applications. It provides an applications-oriented approach to materials analysis written primarily for physicist, Chemists, Agriculturalists, Electrical Engineers, Mechanical Engineers, Signal Processing Engineers, and the Academic Researchers and for the Graduate Students who will also find it useful as a reference for their research activities.

\title{
How to reference
}

In order to correctly reference this scholarly work, feel free to copy and paste the following:

Chanel Fortier (2012). Fourier Transform Spectroscopy of Cotton and Cotton Trash, Fourier Transform Materials Analysis, Dr Salih Salih (Ed.), ISBN: 978-953-51-0594-7, InTech, Available from: http://www.intechopen.com/books/fourier-transform-materials-analysis/fourier-transform-spectroscopy-ofcotton-and-cotton-trash

\section{INTECH}

open science | open minds

\author{
InTech Europe \\ University Campus STeP Ri \\ Slavka Krautzeka 83/A \\ 51000 Rijeka, Croatia \\ Phone: +385 (51) 770447 \\ Fax: +385 (51) 686166 \\ www.intechopen.com
}

\author{
InTech China \\ Unit 405, Office Block, Hotel Equatorial Shanghai \\ No.65, Yan An Road (West), Shanghai, 200040, China \\ 中国上海市延安西路65号上海国际贵都大饭店办公楼 405 单元 \\ Phone: +86-21-62489820 \\ Fax: +86-21-62489821
}


(C) 2012 The Author(s). Licensee IntechOpen. This is an open access article distributed under the terms of the Creative Commons Attribution 3.0 License, which permits unrestricted use, distribution, and reproduction in any medium, provided the original work is properly cited. 